\title{
The iso-Score Curve Graph. A new tool for competitive bidding
}

Article

Accepted Version

Ballesteros-Pérez, P., González-Cruz, M. C., Pastor-Ferrando, J. P. and Fernández-Diego, M. (2012) The iso-Score Curve Graph. A new tool for competitive bidding. Automation in Construction, 22. pp. 481-490. ISSN 0926-5805 doi: https://doi.org/10.1016/j.autcon.2011.11.007 Available at https://centaur.reading.ac.uk/51056/

It is advisable to refer to the publisher's version if you intend to cite from the work. See Guidance on citing.

Published version at: http://dx.doi.org/10.1016/j.autcon.2011.11.007

To link to this article DOI: http://dx.doi.org/10.1016/j.autcon.2011.11.007

Publisher: Elsevier

All outputs in CentAUR are protected by Intellectual Property Rights law, including copyright law. Copyright and IPR is retained by the creators or other copyright holders. Terms and conditions for use of this material are defined in the End User Agreement.

\section{www.reading.ac.uk/centaur}

\section{CentAUR}

Central Archive at the University of Reading 
Reading's research outputs online 


\title{
THE ISO-SCORE CURVE GRAPH. A NEW TOOL FOR COMPETITIVE BIDDING
}

\section{Authors:}

\author{
Ballesteros-Pérez, $\mathrm{P}^{\mathrm{a}}$; González-Cruz, $\mathrm{M}^{\mathrm{a}}$ Carmen ${ }^{\mathrm{b}}$;
}

Pastor-Ferrando, Juan Pascual ${ }^{\text {c; }}$ Fernández-Diego, Marta ${ }^{\text {d }}$

${ }^{a}$ Head of Construction studies in Depuración de Aguas del Mediterráneo SL (Spain).

$\mathrm{PhD}$. and Msc. in Civil engineering.

Depuración de Aguas del Mediterráneo S.L. C/Guglielmo Marconi 11, 2nd, office 19 Parque Tecnológico 46980 Paterna (Valencia, Spain)

Part-time Lecturer in Departamento de Ingeniería del Terreno. Escuela Técnica Superior de Ingenieros de Caminos, Canales y Puertos. Universitat Politècnica de València. $C^{\circ}$ de Vera $s / n$, 46022 Valencia, Spain

Phone: +34 902881510 (ext.: 366) Fax: +34 963531225.

E-mail : pabbalpe@trr.upv.es

b Lecturer in Departamento de Proyectos de Ingeniería. Escuela Técnica Superior de Ingenieros Industriales. Universitat Politècnica de València. $C^{\circ}$ de Vera s/n, 46022 Valencia, Spain PhD. Industrial Engineering.

Phone: +34 963879866 (ext.:75654 ) Fax: +34 963879869 (ext.:79869 ).

E-mail: mcgonzal@dpi.upv.es

Corresponding author

c Lecturer in Departamento de Proyectos de Ingeniería. Escuela Técnica Superior de Ingenieros Industriales. Universitat Politècnica de València. $C^{\circ}$ de Vera s/n, 46022 Valencia, Spain

PhD. Industrial Engineering.

Phone: +34963 879869 (ext.:75658 ) Fax: +34 963879869 (ext.:79869)).

E-mail: jppastor@dpi.upv.es

c Lecturer in Departamento de Organización de Empresas. Facultad de Administración y Dirección de Empresas. $\mathrm{C}^{\circ}$ de Vera s/n, 46022 Valencia, Spain

PhD. Telecommunications Engineering.

Phone: +34 963877685 (ext.:76850 ) Fax: +34 963879779 (ext.:79779).

E-mail: marferdi@omp.upv.es 


\title{
THE ISO-SCORE CURVE GRAPH. A NEW TOOL FOR COMPETITIVE BIDDING
}

\begin{abstract}
The present work describes a new tool that helps bidders improve their competitive bidding strategies. This new tool consists of an easy-to-use graphical tool that allows the use of more complex decision analysis tools in the field of Competitive Bidding. The graphic tool described here tries to move away from previous bidding models which attempt to describe the result of an auction or a tender process by means of studying each possible bidder with probability density functions.
\end{abstract}

As an illustration, the tool is applied to three practical cases. Theoretical and practical conclusions on the great potential breadth of application of the tool are also presented.

Keywords: bid, tender, auction, construction, score, graph.

\section{Introduction}

The volume of economic transactions conducted by competitive bidding gives importance both to the study of auctions as a part of basic research in economics and management science [1], and to the evaluation of assistance bidding practitioners can get from the advances made in auction theory [2]. Hence, research in the area of competitive bidding strategy models has been in progress since the 1950s [2-12].

The standard behavioral presumption of mainstream auction theory is that bidders: behave rationally, and presume that their rivals and the seller behave rationally [11].

Numerous competitive bidding strategy models have been developed that predict the probability of a bidder winning an auction [7, 8]. However there is no generally acceptable approach to solve real bidding problems, in particular the models based on the theory of Games, Decision Analysis and Operational Research are difficult to apply to real-world business contexts largely because of the complex mathematical formulations used in the models and/or because the models do not suit the actual practices [2, 8,11$]$.

Because of the complexity in the application of such models to public tenders $[2,7,8,11,13$ -16], where multiple technical and financial criteria are involved, there is still a need for the development of new tools that help decision makers and improve the selection process of candidate contractors in any kind of public tender, thus extending their field of application to tender contests. 
The present work presents a new practical tool that can help potential bidders improve their competitive bidding strategies and increase their chances of winning a contract. This tool constitutes a new graph that aims to enable bidders to place their bids thanks to previous bidding experiences and according to simple statistical procedures.

\section{Main previous works}

A great body of knowledge exists on the theory of auctions and competitive bidding that is of potential relevance to construction contract tendering. Most of this, however, contains assumptions—such as perfect information—-that are unlikely to be tenable in practice [19].

The large literature on bidding theory and models (see Stark and Rothkopf, 1979, [20] for an early bibliography) is replete with what can be termed 'the statistical hypothesis' in that auction bids are assumed to contain statistical properties such as fixed parameters and randomness [16].

The first contributions (e.g., Friedman, 1956 [21]) assumed that each bidder drew bids from a probability distribution unique to that bidder, with low-frequency bidders being pooled as a special case.

Pim (1974) [22] analysed a number of projects awarded to four USA construction companies. His study indicated that the average number of projects acquired is generally proportional to the reciprocal of the average number of bidders competing - the proportion that would be expected to be won by pure 'chance' alone. That suggested an extremely simple 'equal probability' model in which the expected probability of entering the lowest bid in a k-size auction, that is, an auction in which $\mathrm{k}$ bidders enter bids, is the reciprocal of $\mathrm{k}$.

Later work by McCaffer and Pettitt (1976) [23] and Mitchell (1977) [24] for example, assumed the probability distributions to be non-unique and homogeneous, enabling a suitable distribution shape to be empirically fitted (uniform, in the case of McCaffer and Pettitt) and the derivation of order statistics based on an assumed (normal) density function.

Since then, most of the bidding literature has been concerned with setting a mark-up, $m$, so that the probability, $\operatorname{Pr}(m)$, of entering the winning bid reaches some desired level. Several models have been proposed for calculating $\operatorname{Pr}(m)$ [25], among them, four main approaches have been: Friedman's [21], Gates' [26], Carr's [27] and Skitmore's [28] models.

All these models are based on the same statistical model but differ in their detailed assumptions of its specification. Nevertheless, previous work in auction bidding has to a large extent been carried out without any real supporting data. In fact, in the context of construction contract auction bidding, it has been doubtful that sufficient data can be mustered for each bidder for any effective predictions to be made [16]. 
By means of analysing some real and typical sets of auction bid data it has been possible to compare the aforementioned major models against pure chance and each other, showing that all offer an improvement on chance with multivariate models generally giving the best results [16].

Later empirical work by Skitmore (1991) [28] showed the homogeneity assumption to be untenable for real datasets of construction contract auctions, at least insofar as its superiority in predicting the probability of lowest bidders is concerned (Skitmore, 1999) [16]. Runeson and Skitmore (1999) [29], however, have cast doubt on the whole future of the heterogeneous approach to modelling construction contract auction bids on the basis of its necessary, but forced, assumption of temporal invariance (fixed parameters) in the absence of the lengthy repeated trials assumed by the statistical model - each bidder not bidding frequently enough to generate a reasonable size dataset.

The benefits of using these models in practice are, however, like the models themselves, statistical in nature. Like professional gamblers, proficient bidders given even a slight edge over chance should be able to exploit this to advantage over a period of time [16].

The graphic tool described later will enable bidders representing bidding historical data and inferring patterns of competitors' behavior in a way not studied before. Whereas previous models are mainly based on probabilistic description of groups of single bidders, the new bid tender forecasting model (BTFM hereinafter), whose first part is constituted by the graphical tool described afterwards, will describe group patterns while bidding.

This alternative viewpoint will allow us: (1) to study bidding behaviors with a significant small database compared to previous works; (2) to forecast the probability of getting a particular position within the group of competitors, and (3) to analyse time variations between tenders. The advantages of the new model we are going to explain solve the major problems that almost all of the previous models currently have.

However, due to the lack of space needed to show the whole BTFM, in this paper only the first model's tool will be shown: the iso-Score Curves Graph, which enables us to represent, on a convenient canvas, the bidding data and statistical functions that will be explained in upcoming articles.

Finally, apart from BTFMs described above, formal and analytical risk models have been developed in order to prescribe how risk should be incorporated into construction bids, however, in real practice, priced risks may be excluded from the final bid to enhance competitiveness [30]. 
Although risk apportionment affects a contractor's pricing strategy, other complex microeconomic factors also affect price. Therefore some other recent but lighter conceptual models have been developed for use by contractors as part of a more informed approach in identifying key competitors, and as a basis for formulating bidding strategies [31]. The competitiveness between bids is then examined by means of linear mixed models according to variables such as: project type and size, work sector; work nature; market conditions and number of bidders [32]. The BTFM proposed in the future will not involve risk issues, so this kind of model will be a useful complement to the proposed one.

\section{Background. Auctions vs Tenders}

In general there are many different forms of auctions and several useful ways of classifying these variants. A "standard" auction means one in which the winner is the highest bidder among potential buyers, or the lowest bidder among potential sellers. The distinction between contexts in which bidders are competing to buy and to sell is relatively unimportant: there is an almost perfect correspondence in results. In what follows, we will normally not comment further on the difference between bidding to buy and bidding to sell [2].

Most bidding theory papers discuss a single isolated auction of a single indivisible asset. The most common exception is papers discussing an isolated sale, usually simultaneous but perhaps sequential, of a fixed number of identical assets to bidders, each of whom attach no value to a second purchase; these are typically called "multiunit" auctions [33, 34]. Parallels to single-asset auctions exist, but are incomplete.

Auctions can be either "open" or "closed." In open auctions, prices are publicly announced and bidders can indicate their willingness to transact at the particular prices. In closed auctions, bidders submit offers simultaneously, and these offers are then evaluated by the bid-taker.

Open auctions can be "progressive" as in the familiar "English auction" in which the auctioneer solicits successively better offers until no bidder is willing make a better bid. Alternatively, they can be "Dutch auctions" where the auctioneer (or now an electronic device) announces successively lower prices until a bidder bids and thereby wins the right to the lot for sale.

By far the most common closed auction form is standard sealed bidding. However, there is an alternate form that is used only occasionally. It was proposed by Vickrey (1961) [34] in a partially successful attempt to devise a closed procedure strategically equivalent to the English auction. In such "Vickrey auctions" of single items, the winning bidder is the one who submitted the best bid, but the price is set at the level of the second-best bid [34]. 
Thus, it is called a "second-price auction" in contrast to standard sealed bidding and Dutch auctions which are called "first-price auctions" since the winner's price is the best price offered. English auctions are considered second-price auctions, because the transaction price is at the level of (or marginally better than) the best price acceptable to any losing bidder. Multiunit analogues are "discriminatory" auctions (each winner pays the price he bid) and "highest-rejected-bid" auctions [35].

On the other hand, the low-bid method may result in a contract with a firm that submits either accidentally or deliberately an unrealistically low-bid price. Such an occurrence hurts both the owner and the contractor by promoting disputes, increased costs, and schedule delays. To address this problem, other countries have adopted bidding methods based on the average of the bids submitted. One such approach is the below-average method where the winning bid is closest to but below the average of all bids [36].

Finally, auctions also blend into request-for-proposal processes. Some such processes are essentially auctions. In others the rules for evaluating proposals are not well understood by the bidders, and the proposals may be the first step in a relatively unstructured negotiation process [2].

McAfee and McMillan (1987) [37], Wilson (1992) [38], and Klemperer (1999) [39] provide surveys of auction theory; Stark and Rothkopf (1979) [20] attempt a comprehensive bibliography; Krishna (2002) [40] gives some degree of literature survey in a book intended for a graduate course; and Klemperer (2004) [41] and Milgrom (2004) [42] include literature surveys aimed at somewhat broader audiences.

However, many studies in the literature are concerned with the analysis of bidding behavior of contractors in auctions but not in tender contests [6- 9, 13, 25, 28, 43]. In tenders, the contract is awarded depending on a number of technical and financial criteria. Auctions can be considered a simple type of tender as the contract is awarded using a single criterion: the economic one [8, 16, 44] no matter how this criterion is implemented: English or Dutch auction, Open or Closed auction, Sealed-bid or Vickrey auction. The economic criterion most widely used in both processes (auctions and tender contests) is that of "the economically most advantageous bid" [45], the difference being that auctions rely exclusively on the economic criterion whereas tender contests use several technical and financial criteria. In tender contests, the economic criterion is weighted, just like any of the other criteria used in the process [46].

Many recent studies that develop ranking models for the unbiased prioritization of bidders [2, 8, 46-51] are based on multi-criteria decision analysis models [52-56] in detriment of the use 
of weighted financial factors. Even more recently some models facilitate and optimize the procedures of bidding by means of electronic systems $[55,57]$.

However, the tool proposed later and the whole bid tender forecasting model (BTFM), that will be eventually explained, is not linked to any previous multi-criteria decision method, indeed it is not a multi-criteria tool. The aim of the BTFM is exclusively to represent the probability that each economic bid has of obtaining a particular score, position or, even, being considered risky by the owner. No other criteria will be involved but the economic one. In other words, whereas multi-criteria tools are usually applied to rank and weight several tender items (normally technical, administrative and economical items) but only as a whole, the BTFM will study the economic criterion in depth, trying to identify which range of potential bids have higher probabilities to win.

Returning to the difference between auctions and tenders, the procedure to award a contract is different in either contest case:

1. In auctions, the winner will be the bidder with the economically most advantageous and non-abnormally low bid among candidate bidders. Therefore, the key issue in auctions is the final ranking of bidders. There is no need to assign an economic score to each bidder since the cheapest one will be the winner, though the bidder will not necessarily be awarded the contract with the lowest bid (e. g. Vickrey auctions).

2. In tender contests, the winner will be the best-scored bidder ranked according to a scoring system (known in advance and specified in the tender conditions, which usually includes administrative, technical and economic issues). For example, the performance of every economic proposal is rated for each evaluation factor (Maximum Bid, Average Bid, and so on) and generally, although not always, those proposals which deviate from the average are eliminated.

Therefore, the qualitative difference between auctions and tender contests, from an economic perspective, is a more complex issue as the contestants' bids have to be "scored" (rather than "ranked").

The criterion of economic scoring in public tender is a key issue since the score obtained will be further aggregated to the values obtained in the technical and financial criteria thus generating the final rank of bidders. In other words, the particular Economic Scoring Formula chosen by the owner to distribute the total amount of points, by which the economic part of the tender is being evaluated, is not trivial. This ranking will determine the most suitable bidders for contract award and, possibly, different Economic Scoring Formulas will lead to different bidder rankings. 
The scores assigned to the technical factors and bid price of the proposals participating in a bidding process depend on the following two factors $[46,58,59]$ :

- The relative weights (weighing) of the technical factors against the financial factors for each particular bid situation. It is not the same that in a tender the economic part involves only $35 \%$ (for instance) of the complete scoring factors, but that the economic element equals 100\% (an auction, not a tender, as we have defined). Probably, the behavior of bidders will show different scales of economic aggressiveness.

- The mathematical model used to compare the bidders' bids for the technical and financial factors under consideration (Economic Scoring Formulas).

The main reason why multi-criteria decision models have been extensively used for ranking bidders is because subsequent sensitivity analyses have demonstrated that the final bidders' ranking greatly differs depending on the criteria and weights used in the evaluation process $[46,50]$. But, as was previously said, the proposed tool focuses on the study of economic probabilities getting a certain economic score, obviating other tender items.

\section{Basic definitions}

Public Administrations in different countries use different terms to refer to the same tender concepts. Additionally, some terms used in this paper do not match the standards of the Spanish Public Administration. Therefore, for clarity we will define some of the terms used in this work:

"Economic Scoring Formula" (ESF) is the set of mathematical expressions that are used to assign a certain numerical value to each bidder from his/her bid price expressed on a monetary-unit basis. ESF includes the mathematical operations that provide the score and the mathematical formula that determines which bids are considered abnormal or risky (Abnormally Low Bids Criteria (ALBC). ALBC has received much less attention in the literature than the analysis of contractor's bidding behavior [60].

"Scoring Parameter"(SP). SP refers to the variables that allow ESF to be operational. They are calculated from the distribution of the bids participating in a tender contest.

"Bidder Drop (D). It is the discount or bid reduction in the initial price of a contract submitted by a given contractor for a particular contest. It is mathematically expressed as:

$$
D_{i}=1-\frac{B_{i}}{A}
$$


Where $D_{i}$ is the Drop (expressed in per-unit values) of bidder " $i$ ", $B_{i}$ is the Bid (expressed in monetary values) of bidder "i", and $A$ is the initial Amount of money (in monetary values) of the Tender (generally set by the Public Administration).

ESF scores result from the input of the bidders' bids $\left(B_{i}\right)$ (in monetary values) or through the transformation of bidders' bids into Drops $\left(D_{i}\right)$ (in per-unit values). Both options have advantages, but for the comparison of bids in different bidding processes, with different initial bid amounts $(A)$, it will be better to work with Drops $\left(D_{i}\right)$ than with Monetary-based Bids $\left(B_{i}\right)$.

\section{Fieldwork}

In order to have a number of representative ESF from different bidding processes for further analysis and SP ranking, a total of 120 real tender documents of Spanish Public Administrations and private companies were collected.

The dataset collected and analyzed is sufficiently representative as it comprises: Tender contests and Auctions, all kinds of public administrations (City Councils, local councils, semipublic entities, universities, ministries, and so on), a great variety of civil engineering works and services, representation of different geographical regions (including the islands) and a wide range of Tender Amounts. Although the sample only contains Spanish tender documents, the ESF and SP analyzed are common to those used in any country where the Administration sets an initial Tender Amount (A) against which candidates will underbid.

The specification of an initial Tender Amount A allows the use of Bid Drops as the Drop indicates a discount or bid reduction in the price relative to a fixed initial Amount $A$. The tool presented in this paper works well with both Tender Amounts and Bid Drops. The examples presented here have been calculated using Bid Drops expressed in per-unit values.

\section{Scoring Parameters Classification}

The Economic Scoring Formulas of the 120 contract documents have been calculated and the corresponding SP have been classified into two groups: Primary SP and Secondary SP.

The Primary SP are base line or reference parameters from which the Secondary SP are calculated.

The Primary SP are:

- Mean Drop, " $D_{m}$ "; It is the mean value of the Bid Drops submitted by the total number of bidders admitted in a particular tender contest. The relation with the Mean Bid $\left(B_{m}\right)$ in monetary values is: $B_{m}=\left(1-D_{m}\right) A$ 
- Maximum Drop, " $D_{\max }$ "; it is the per-unit Drop corresponding to the Minimum Bid submitted by the bidders. Its relation with the Minimum Bid $\left(B_{\min }\right)$ in monetary value is: $B_{\min }=\left(1-D_{\max }\right) A$.

- Minimum Drop, " $D_{\text {min"; }}$ it is the per-unit Drop corresponding to the Maximum Bid submitted by the bidders. Its relation with the Maximum Bid $\left(B_{\max }\right)$ in monetary value is: $B_{\max }=\left(1-D_{\min }\right) A$.

- Drops' Standard Deviation, (Drops' stdev), “б”; in certain project-level-of-risk criteria it is typical to express bid rates on a percent basis relative to the Standard deviation values of the bids. Its relation with Bids' Standard Deviation (S) (Bids' stdev) in monetary value is: $S=\sigma \cdot A$.

The second group of SP consists of the Secondary SP. As mentioned above, they result from the calculation of one or more primary SP. The Secondary SP are:

- Abnormal Drop " $\mathrm{D}_{\mathrm{abn}}$ " is the Drop Threshold value; bids below this threshold value will be considered abnormal or risky. The Abnormal Drop is calculated with a formula that includes some primary SP such as $D_{m}$ (for example, a certain percentage value lower than the Mean Drop). Its relation with Abnormal Bid $\left(B_{a b n}\right)$ in monetary value is: $B_{a b n}=\left(1-D_{a b n}\right) A$; when $D_{a b n}$ is calculated as a distance from average $T$ (in perunit values) relative to $D_{m}$, the expression is: $D_{a b n}=1-(1-T)\left(1-D_{m}\right)$.

- Corrected Mean Drop, " $D_{m c}$ "; it consists of an adapted $D_{m}$, usually obtained after rejecting extremely high/low bids or bids included within a certain range of margin, e.g. $D_{m} \pm \sigma$.

- Allowable Maximum Drop, " $\mathrm{D}_{\max }$ "; is the maximum non-risk or abnormal bid drop.

- Complex Parameters. ESF may require the use of parameters calculated from one or several primary SP with different mathematical criteria. Through a single mathematical expression that operates with "Absolute Values" over certain primary $\mathrm{SP}$, Complex Parameters allow the generation of a new curve that represents very different scoring intervals. It is used for very unusual ESF and SP.

Primary and Secondary SP are combined mathematically to generate specific ESF for each particular bid situation and should be clearly specified in the contract conditions of the tender. 


\section{The iso-Score Curve Graph}

The iso-Score Curve "iSC" is defined as the geometrical region of points associated with the bids submitted by a bidder and scored with the same number of points according to a known ESF.

An iso-Score Curve Graph "iSCG" is a 2D graphical representation with the following features:

- It represents an ESF Score Parameter on axis X

- It represents Bidders' Drop $\left(D_{i}\right)$ on axis $Y$

- It represents the iso-score curves of the ESF at predefined scoring intervals $\left(\mathrm{S}_{\mathrm{i}}\right)$

Iso-score curves can represent score values; for example, for an ESF that distributes up to 50 points among the bidders, we can obtain 50-point, 45-point, 40-point curves ... up to the 0 -point curve. Additionally, iso-score curves can also represent a value-scale in per-unit values; in our example, the 1-iso-score curve corresponds to the 50-point curve, the 0.90iso-score curve to the 45 -point curve, the 0.80 -iso-score curve to the 40 -point curve, and so on.

The use of per-unit curves is much more advisable as their value is independent of the weighing of the financial factors relative to the technical factors.

The procedure to generate iso-Score Curves from the ESF is as follows:

1. Express mathematically the Economic Scoring formula.

2. Convert the ESF (when expressed in monetary units) into Drops (with parameters expressed in per-unit values).

3. Express the ESF in terms of a single Score Parameter, SP, (when the ESF contains more than one SP) for the $2 \mathrm{D}$ representation of the parameters.

4. Calculate variable Di (Bidders' Drop) from the expression of the ESF obtained in the previous step.

5. Represent the different iSC graphically for the required and/or selected score values $\left(S_{i}\right)$.

Following, this procedure is applied to three case studies for the generation of iSCG. We have developed three case studies so as to cover the most typical ESF found in Spanish tender contests, in terms of SP and abnormal or project-risk criteria.

Based on the information provided by the representation of the iSCG of these three ESF, the iSCG of other less typical ESF can be obtained. 
The procedure to obtain these iSCG follows the 5 steps described above. In order to simplify the text, the equations for each step will be included in the appendix, starting from the second step.

\subsection{Mathematical expression of the ESF}

The mathematical expression of the ESF should be specified by the Public Administration or the owner in the contract documents of the tender; however sometimes it is expressed in linguistic terms rather than numerically. In such a case, the first step will be to express the ESF mathematically.

\section{Case 1:}

The ESF is represented by the following mathematical expressions:

$$
S_{i}=50\left(1-\frac{B_{i}-B_{\min }}{B_{\min }}\right) \text { and } B_{a b n}=(1-T) B_{m}
$$

Where:

$\mathrm{S}_{\mathrm{i}}=$ Score of bidder "i". Assume that, according to the contract conditions of the tender contest, bidders can get scores between 0 and 50 points $\left(0 \leq S_{i} \leq 50\right)$. For the expression of the score in per-unit values, value 50 will be replaced by 1 .

$B_{i}$ : Bid price in monetary value of bidder " $i$ " for the execution of the contract

$B_{\min }$ : The lowest allowable bid (but not abnormally low bid), i.e. $B_{\min }>B_{a b n}$, proposed by the bidders.

$B_{a b n}$ : Bid Price in monetary value below which the bid is considered abnormally low.

T: Abnormally High Drop Threshold. For the case study under consideration the documents of the tender contest set a value of $10 \%(0.10)$.

$B_{m}$ : Mean value of the bids in monetary value.

\section{Case 2:}

$$
S_{i}=35 \frac{A-B_{i}}{A-B_{\text {min }}} \text { and } B_{\text {abn }}=B_{m}-2 S
$$

Where:

$A$ is the initial contract price (tender Amount) in monetary value (set by the Administration).

$S_{i}$ : Score of bidder "i" . Assume that, according to the tender conditions, bidders can get scores between 0 and 35 points $\left(0 \leq S_{i} \leq 35\right)$. For the expression of the score in per-unit values, value 35 will be replaced by 1 . 
$S$ : Standard deviation of the bids in monetary value.

$B_{i}, B_{\min }, B_{a b n}$ and $B_{m}$ are the same parameters as those used in Case 1.

\section{Case 3:}

$$
S_{i}=40-10 \frac{B_{i}-B_{\min }}{B_{m}-B_{\min }} \text { and } B_{a b n}=(1-T) A
$$

Where all variables have been described in the case studies above. Let $S_{i}$ (according to some hypothetical tender conditions) be between 0 and 40 points $\left(0 \leq S_{i} \leq 40\right)$. For the expression of the score in per-unit values, value 40 will be replaced by 1 and value 10 by 0.25 .

Assume that in this example the tender document sets the Abnormally High Drop Threshold (T) to $30 \%(0.30)$.

\subsection{Transformation of the ESF into Drops}

This step is required when ESF is not expressed in per-unit Drops but in monetary values. The necessary expressions for the transformation of ESF into Drops are:

$$
\begin{gathered}
B_{\min }=\left(1-D_{\max }\right) A ; \quad B_{\max }=\left(1-D_{\min }\right) A ; \quad B_{m}=\left(1-D_{m}\right) A ; \\
B_{a b n}=\left(1-D_{a b n}\right) A ; S=\sigma \cdot A
\end{gathered}
$$

Basically it comes down to a matter of changing $B_{x}$ variables for $D_{x}$ variables, with $x$ equals $m$, min, max or abn.

The expressions of the three cases in per-unit Drops, assuming that $S_{i}$ is also expressed in per-unit values, are shown in the appendix for: Case 1 (equation A1.2), Case 2 (equation A2.2) and Case 3 (equation A3.2).

\subsection{Expressing ESF in terms of a single Scoring Parameter}

Taking into account that the iSCG puts in the X-axis an SP, the ESF must be expressed in function of a single SP, otherwise it is impossible to represent a $2 \mathrm{D}$ graph.

Any parameter can be used to express ESF, but it is better to use a parameter already expressed mathematically (e.g. $D_{m}$ and/or $D_{\max }$ ).

For the transformation of a multi-parameter ESF into a single-parameter ESF it is necessary to know the following proposed primary relations between scoring parameters:

$$
\mathrm{D}_{\max }=\mathrm{D}_{\mathrm{m}}^{\mathrm{a}} ; \quad \mathrm{D}_{\min }=\mathrm{D}_{\mathrm{m}}^{\mathrm{b}} ; \quad \sigma=\mathrm{K}\left(\mathrm{D}_{\max }-\mathrm{D}_{\min }\right)
$$


These relations were obtained from the analysis of the 120 contract documents of Spanish Public Administrations and Private Companies. Note that $D_{m}, D_{\min }$ and $D_{\max }$ are correlation curves that cross points $(0,0)$ and $(1,1)$, whereas the fitting curve of $\sigma$ always crosses $(0,0)$ and $(1,0)$.

In addition, the correlation between variables depends on random coefficients $(a, b$ and $K)$. These coefficients are obtained from any recent record data belonging to the same Administration and using the same ESF.

After the identification of the correlation curves that best correlate the scoring parameters, the expressions of the case studies are shown in the appendix: Case 1 (equations A1.3a and $A 1.3 b$ ), Case 2 (equations A2.3a and A2.3b) and Case 3 (equations A3.3a and A3.3b).

Note that $\mathrm{a}, \mathrm{b}, \mathrm{K}$ and $\mathrm{T}$ are coefficients of known value whose numerical determination is necessary for the representation of the iso-Score Curves.

\subsection{Calculate variable $\mathrm{D}_{i}$ from the ESF}

Starting from the expressions calculated in the previous step, it is a matter of working out the value of $D_{i}$ and $D_{a b n}$. The following results are obtained for each case study in the appendix: Case 1 (equations A1.4a and A1.4b), Case 2 (equations A2.4a and A2.4b) and Case 3 (equations $A 3.4 a$ and $A 3.4 b)$.

When seeing step 4's equations note that it was not necessary to perform additional transformations over the expressions of $D_{a b n}$ since $D_{a b n}$ is actually a curve ready to be represented once the values of $D_{m}$ or $D_{\max }$ are known.

\subsection{Plotting the iso-Score Curves}

Finally, variable $S_{i}$ has to be equalled to the values whose score is to be represented. In the cases under analysis, the following values were selected: $1,0.9,0.8,0.7,0.6,0.5,0.4,0.3$, $0.2,0.1$ and 0 .

To facilitate the obtaining of numerical values the following generic values were assigned: $a=0.85, b=1.50$ and $K=0.30$ (the numerical values should be obtained from the analysis of the databases of each public administration for a given ESF, as aforementioned) and the values of $T$ mentioned above ( $T=0.10$ in Case 1 and $T=0.30$ in Case 3 ).

From the data and representation of these 11 curves plus the $D_{a b n}$ curve for each case under analysis, we obtain the following graphs whose numerical data are shown in the appendix: Case 1 (Table 1), Case 2 (Table 2) and Case 3 (Table 3). 


\section{Case 1:}

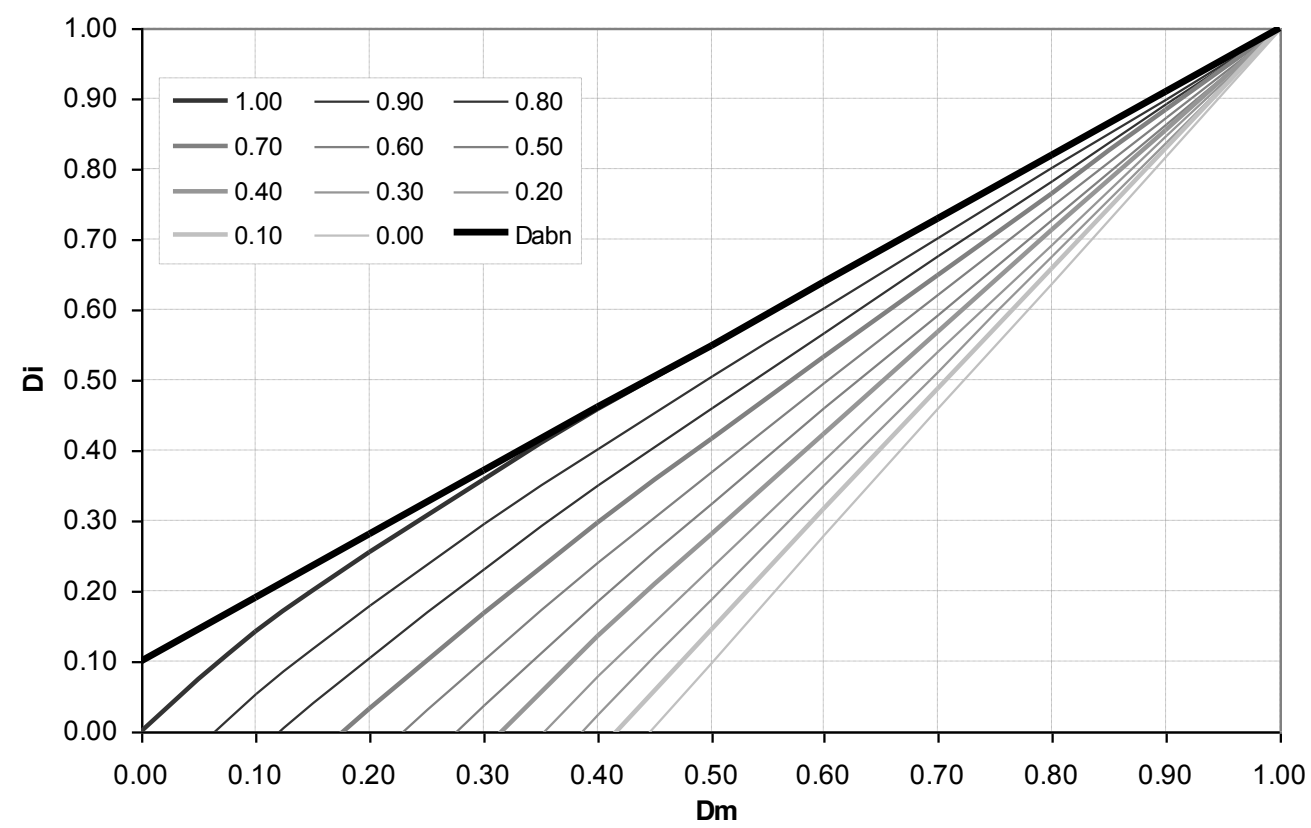

Figure1.1: iso-Score Curve Graph of Case 1 for the Mean Drop $\left(D_{m}\right)$

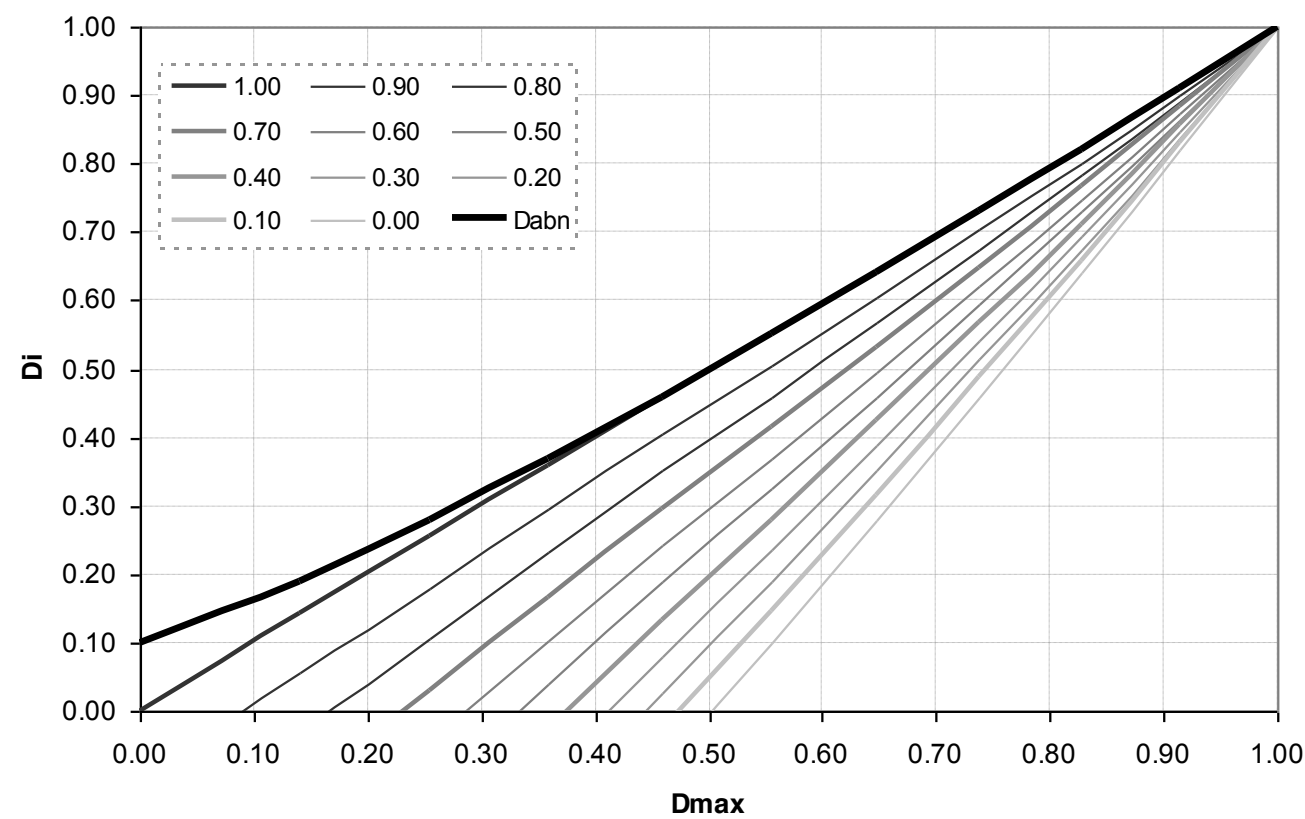

Figure 1.2: iso-Score Curve Graph of Case 1 for the Maximum Drop $\left(D_{\max }\right)$ 


\section{Case 2:}

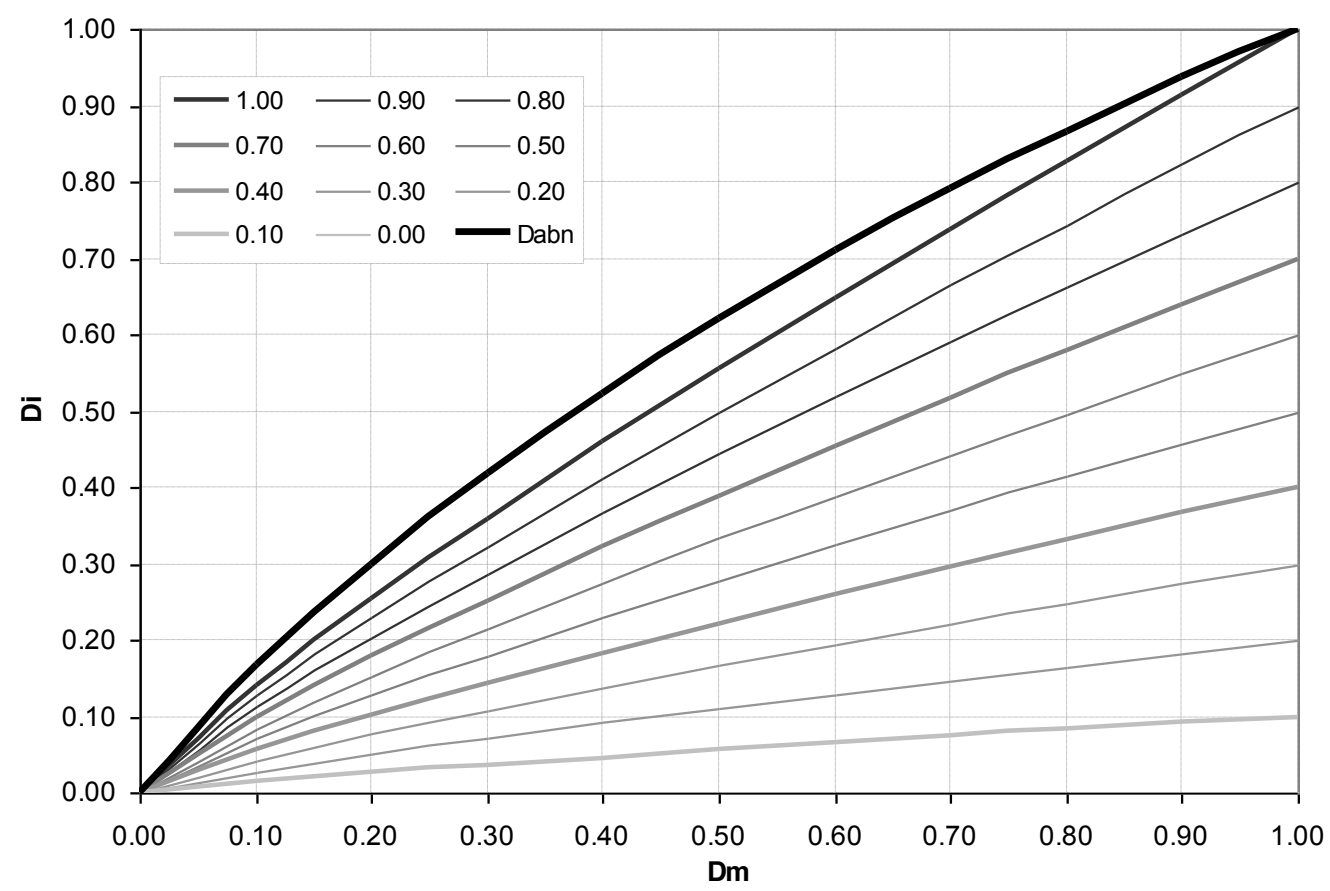

Figure 2.1: iso-Score Curve Graph of Case 2 for the Mean Drop $\left(D_{m}\right)$

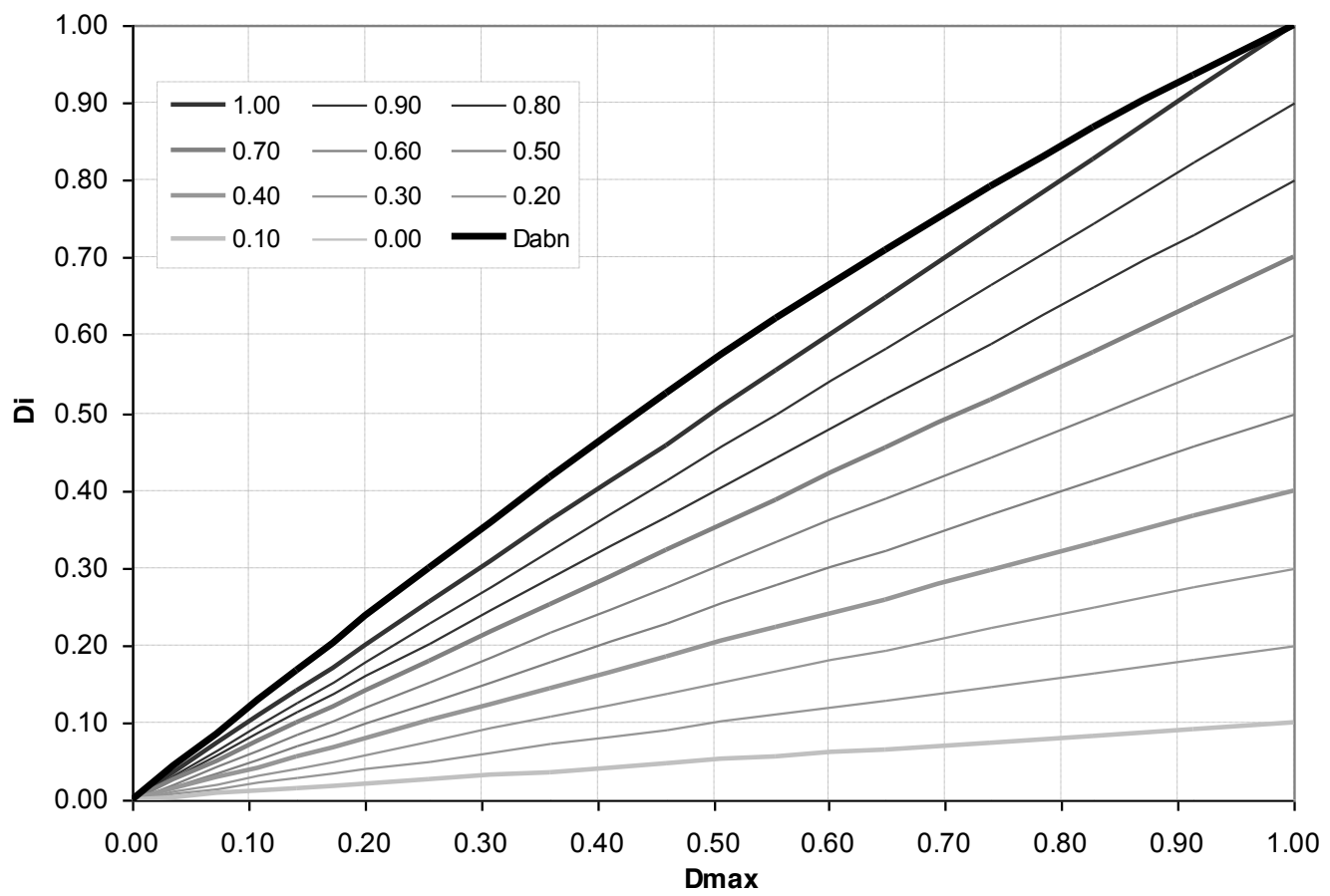

Figure 2.2: iso-Score Curve Graph of Case 2 for the Maximum Drop ( $\left.D_{\max }\right)$ 


\section{Case 3:}

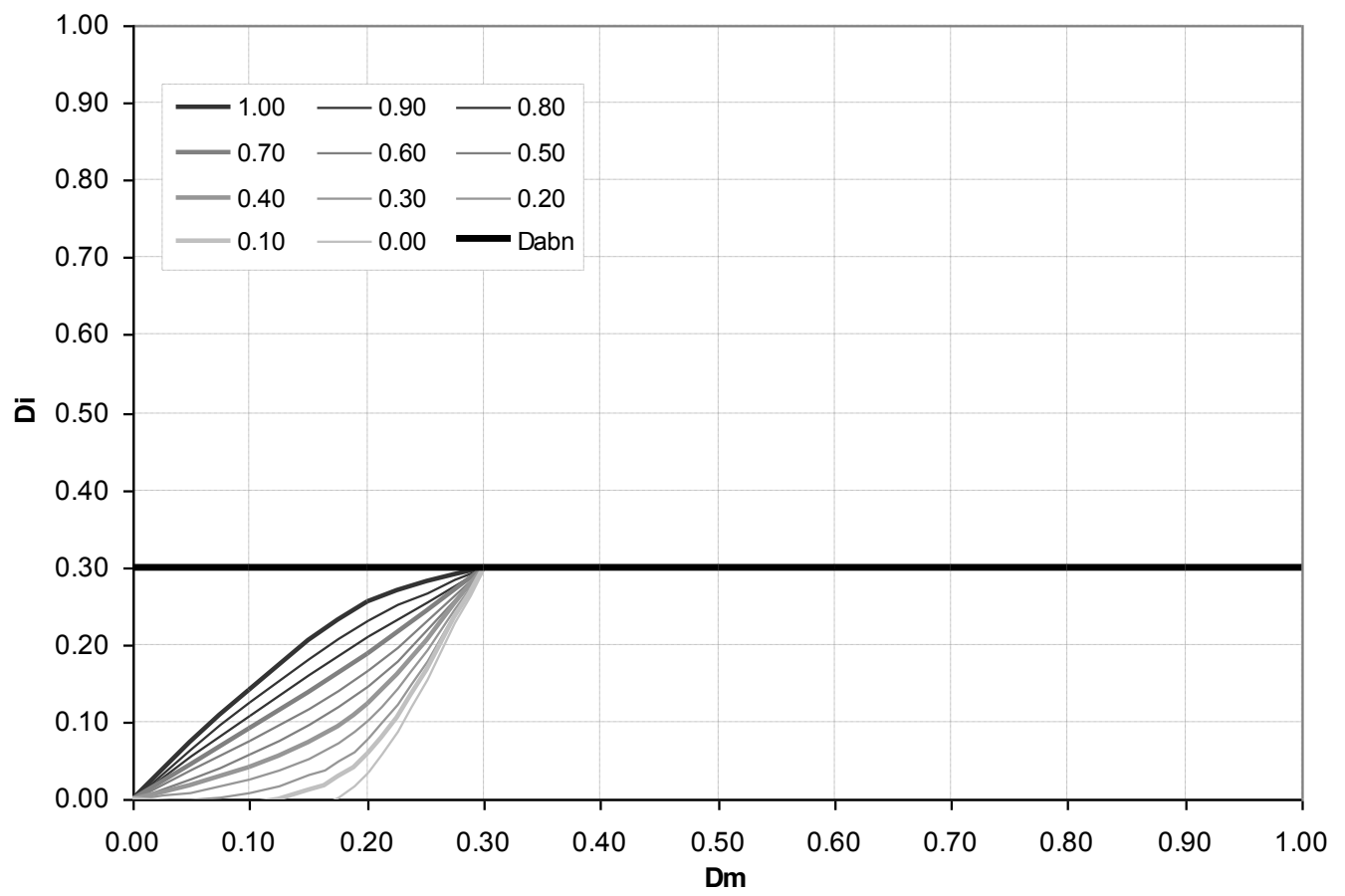

Figure 3.1: iso-Score Curve Graph of Case 3 for the Mean Drop $\left(D_{m}\right)$

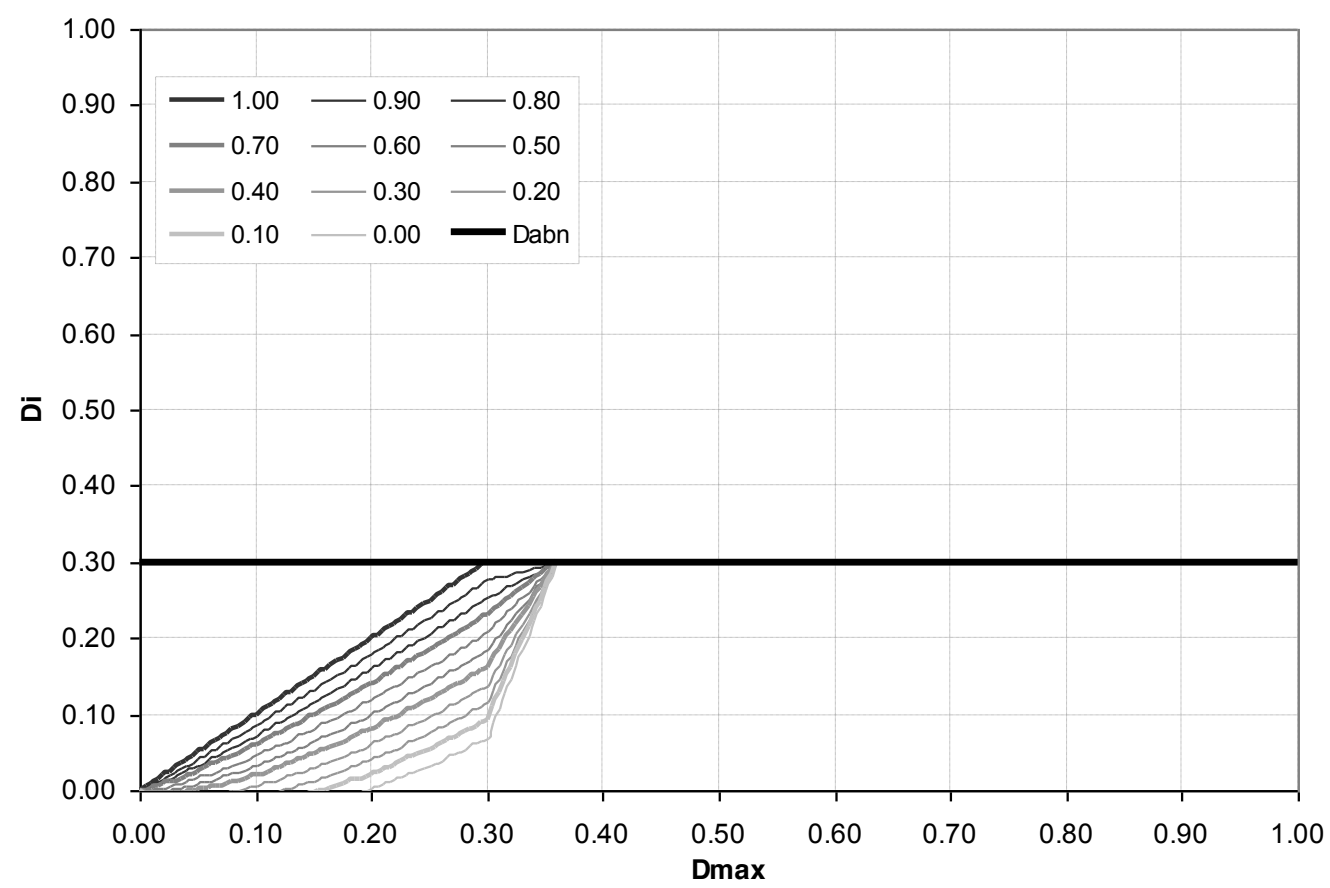

Figure 3.2 iso-Score Curve Graph of Case 3 in for the Maximum Drop ( $\left.D_{\max }\right)$ 


\subsection{Interpretation of the iSCG}

The iSCG allows the visual observation of the distribution of points for a given ESF in a simple way. The analysis of the graphs obtained in the examples reveals that:

\section{Case 1:}

Competitive bids lie within the range $\left[D_{m}, D_{\max }-0,05\right]$; within this range the score values will always be higher than $90 \%$.

It seems difficult to be eliminated by the criterion of abnormally low bid for $D_{m}$ intervals higher than 0.35 (which corresponds to relatively higher $D_{i}$ bids).

\section{Case 2:}

Zero Drop bids should not be presented as the bidder would receive 0 points; additionally the total score significantly drops as the distance from $D_{\max }$ increases.

In the $D_{m}$ range $[0.30,0.70]$ it seems difficult to surpass the Abnormally Low Bid Threshold, which corresponds to the $D_{\max }$ range $[0.36,0.74]$ (a wide range).

It is convenient to set the bid price within the range $0.9 \cdot D_{\max }$ and $1.2 \cdot D_{\max }$, as within this range there are high expectations of being well rated and low probability of being abnormally low.

\section{Case 3:}

As in the case above, Zero Drop bids should not be presented to avoid zero scores, and in this case, $D_{i}$ should never exceed 0.30 .

The probability of getting very low scores for bids below $D_{\max }$ is very high and the risk to exceed the abnormally low bid threshold for drops lower than 0.30 is zero, so that bidders should set their $D_{i}$ close to 0.30 even if substantially sacrificing their estimated profit.

Bidders should try to surpass the $D_{\max }$, so that the bid should lie between $D_{\max }$ and $T$ (equal to 0.30$)$.

\section{Conclusions}

Since it should be kept in mind that sometimes understanding how the Economic Scoring Formula (ESF) in a tender operates is not evident from direct observation of the mathematical expression, iSCGs allow the visual observation of any financial scoring criterion in a simple and graphical form. 
Once the decision maker is trained on its use, the method allows finding aspects of the ESF that can help bidders to set their bids within more advantageous bid margins. On the other hand, also Public Administration might predict bids that are going to receive and integrate them in its own information systems or even decide which ESF should be more suitable for its own tender purposes or aims.

An additional advantage of the use of iSCG is that they allow the representation of tender datasets and greatly help to adjust the regression curves (to determine the values of coefficients $\mathrm{a}, \mathrm{b}$ and $\mathrm{K}$ among others) that will allow a bidder to predict the bids of his/her competitors in future bidding processes. Related to the previous thing, the technologies of the data mining are very useful for the extraction of information of biddings [61]

\section{Discussion. Limitations of the iSCG and Future work}

The iso-Score Curves Graph (iSCG) by itself is only able to represent how a particular ESF distributes the economic points in a certain tender and to identify the relationships between the main Scoring Parameters involved. Finally, it also enables us to know what Bid values will be rejected for being abnormally low or risky.

Nevertheless, in order to constitute a complete Bid Tender Forecasting Model (BTFM) the iSCG must be complemented with further tools and graphs.

In subsequent research it will be shown which are the general mathematical relationships between the main Scoring Parameters and what probabilistic density functions are those which represent their plausible variation values. It will also introduce new Parameters that can be known in advance, that is before the deadline of a tender, that will allow bidders to make bid forecasting; otherwise, it would be impossible to make any kind of predictions.

Once these relationships and parameters have been presented, iso-Score Curves will be used again to generate new types of graphs useful for making predictions.

The nature of information that will enable the whole BTFM outlined in advance aims to be useful to both bidders and owners to predict what different bidding scenarios should be expected once tender specifications have been laid down.

\section{Appendix}

Main abbreviations used in the text:

A Amount of money of a Tender

a regression coefficient to adjust relationship between $D_{\max }$ and $D_{m}$

ALB Abnormally Low Bid 
ALBC Abnormally Low Bids Criteria

B Bid (expressed in monetary value)

b regression coefficient to adjust relationship between $D_{\min }$ and $D_{m}$

$B_{i} \quad$ Bidder's I Bid (expressed in monetary value)

Babn Abnormal Bid (expressed in monetary value)

$B_{m} \quad$ Mean Bid (expressed in monetary value)

$\mathrm{B}_{\max } \quad$ Highest Bid (expressed in monetary value)

$B_{\min } \quad$ Lowest Bid (expressed in monetary value)

BTFM Bid Tender Forecasting Model

D Drop (expressed in per-unit value)

$D_{\text {abn }} \quad$ Abnormal Drop

$D_{i} \quad$ Bidder's $i$ Drop (expressed in per-unit value)

$D_{m} \quad$ Mean Drop (expressed in per-unit value)

$D_{\max } \quad$ Maximum Drop (expressed in per-unit value)

$D_{\max }{ }^{*}$ Maximum Allowable Drop (expressed in per-unit value)

$D_{m c} \quad$ Corrected Mean Drop (expressed in per-unit value)

$D_{\min } \quad$ Minimum Drop (expressed in per-unit value)

ESF Economic Scoring Formula

iSC iso-Score Curve

iSCG iso-Score Graph

$K \quad$ regression coefficient to adjust relationship between $\sigma$ and either $D_{\max }$ and $D_{\min }$

S Bids' Standard Deviation

$\mathrm{S}_{\mathrm{i}} \quad$ Score of the bidder $i$ (can be expressed either in points or in per-unit value)

SP Scoring Parameter

T Abnormally High Drop Threshold

$\sigma \quad$ Drops' Standard Deviation 
Main relationships between variables stated in the text:

$$
\begin{aligned}
& B_{m}=\left(1-D_{m}\right) A \\
& B_{\text {min }}=\left(1-D_{\text {max }}\right) A \\
& B_{\text {max }}=\left(1-D_{\text {min }}\right) A \\
& B_{a b n}=\left(1-D_{a b n}\right) A \\
& D_{i}=1-\frac{B_{i}}{A} \\
& D_{\text {max }}=D_{m}^{a} \\
& D_{\text {min }}=D_{m}^{b} \\
& D_{a b n}=1-(1-T)\left(1-D_{m}\right) \\
& \sigma=K\left(D_{\max }-D_{\text {min }}\right) \\
& S=\sigma \cdot A
\end{aligned}
$$

Equations of iSCGs' Calculation steps for the three cases:

\section{Case 1}

1) $S_{i}=50\left(1-\frac{B_{i}-B_{\min }}{B_{\min }}\right)$ and $B_{\text {abn }}=(1-T) B_{m}$

2) $S_{i}=1-\frac{D_{\max }-D_{i}}{1-D_{\max }}$ and $D_{a b n}=1-(1-T)\left(1-D_{m}\right)$

3) $S_{i}=f\left(D_{\max }\right)=1-\frac{D_{\max }-D_{i}}{1-D_{\max }}$ and $D_{\text {abn }}=f\left(D_{\max }\right)=1-(1-T)\left(1-D_{m}^{\frac{1}{a}}\right)$

$$
S_{i}=f\left(D_{m}\right)=1-\frac{D_{m}{ }^{a}-D_{i}}{1-D_{m}{ }^{a}} \text { and } D_{a b n}=f\left(D_{m}\right)=1-(1-T)\left(1-D_{m}\right)
$$

4) $D_{i}=f\left(D_{\max }\right)=D_{\max }-\left(1-S_{i}\right)\left(1-D_{\max }\right) \quad$ and $\quad D_{a b n}=f\left(D_{\max }\right)=1-(1-T)\left(1-D_{m}^{\frac{1}{a}}\right)$ (A1.4a) 


$$
D_{i}=f\left(D_{m}\right)=D_{m}^{a}-\left(1-S_{i}\right)\left(1-D_{m}^{a}\right) \text { and } D_{a b n}=f\left(D_{m}\right)=1-(1-T)\left(1-D_{m}\right)
$$

5) Table 1: Numerical values of the iso-Score Curves of Case 1

\begin{tabular}{|c|c|c|c|c|c|c|c|c|c|c|c|c|c|c|}
\hline \multirow{2}{*}{ Dm } & \multirow{2}{*}{ Dmax } & \multirow{2}{*}{ Dabn } & \multirow{2}{*}{$\begin{array}{c}\text { Dmax* } \\
\min (\text { Dmax,Dabn })\end{array}$} & \multicolumn{11}{|c|}{ Si (iso-Scoring Curves) } \\
\hline & & & & 1.00 & 0.90 & 0.80 & 0.70 & 0.60 & 0.50 & 0.40 & 0.30 & 0.20 & 0.10 & 0.00 \\
\hline 0.00 & 0.00 & 0.10 & 0.00 & 0.00 & -0.10 & -0.20 & -0.30 & -0.40 & -0.50 & -0.60 & -0.70 & -0.80 & -0.90 & -1.00 \\
\hline 0.10 & 0.14 & 0.19 & 0.14 & 0.14 & 0.06 & -0.03 & -0.12 & -0.20 & -0.29 & -0.37 & -0.46 & -0.55 & -0.63 & -0.72 \\
\hline 0.20 & 0.25 & 0.28 & 0.25 & 0.25 & 0.18 & 0.11 & 0.03 & -0.04 & -0.12 & -0.19 & -0.27 & -0.34 & -0.42 & -0.49 \\
\hline 0.30 & 0.36 & 0.37 & 0.36 & 0.36 & 0.30 & 0.23 & 0.17 & 0.10 & 0.04 & -0.02 & -0.09 & -0.15 & -0.22 & -0.28 \\
\hline 0.40 & 0.46 & 0.46 & 0.46 & 0.46 & 0.40 & 0.35 & 0.30 & 0.24 & 0.19 & 0.13 & 0.08 & 0.03 & -0.03 & -0.08 \\
\hline 0.50 & 0.55 & 0.55 & 0.55 & 0.55 & 0.51 & 0.46 & 0.42 & 0.37 & 0.33 & 0.28 & 0.24 & 0.19 & 0.15 & 0.10 \\
\hline 0.60 & 0.65 & 0.64 & 0.64 & 0.64 & 0.60 & 0.57 & 0.53 & 0.50 & 0.46 & 0.42 & 0.39 & 0.35 & 0.32 & 0.28 \\
\hline 0.70 & 0.74 & 0.73 & 0.73 & 0.73 & 0.70 & 0.68 & 0.65 & 0.62 & 0.60 & 0.57 & 0.54 & 0.51 & 0.49 & 0.46 \\
\hline 0.80 & 0.83 & 0.82 & 0.82 & 0.82 & 0.80 & 0.78 & 0.77 & 0.75 & 0.73 & 0.71 & 0.69 & 0.68 & 0.66 & 0.64 \\
\hline 0.90 & 0.91 & 0.91 & 0.91 & 0.91 & 0.90 & 0.89 & 0.88 & 0.87 & 0.87 & 0.86 & 0.85 & 0.84 & 0.83 & 0.82 \\
\hline 1.00 & 1.00 & 1.00 & 1.00 & 1.00 & 1.00 & 1.00 & 1.00 & 1.00 & 1.00 & 1.00 & 1.00 & 1.00 & 1.00 & 1.00 \\
\hline
\end{tabular}

Table 1: Numerical values of the iso-Score Curves of Case 1

\section{Case 2}

1) $S_{i}=35 \frac{A-B_{i}}{A-B_{\text {min }}}$ and $B_{a b n}=B_{m}-2 S$

2) $S_{i}=\frac{D_{i}}{D_{\max }}$ and $D_{a b n}=D_{m}+2 \sigma$

3) $S_{i}=f\left(D_{\max }\right)=\frac{D_{i}}{D_{\max }}$ and $D_{a b n}=f\left(D_{\max }\right)=D_{m}^{\frac{1}{a}}+2 K\left(D_{\max }-D_{\max }^{\frac{b}{a}}\right)$

$$
S_{i}=f\left(D_{m}\right)=\frac{D_{i}}{D_{m}^{a}} \text { and } D_{a b n}=f\left(D_{m}\right)=D_{m}+2 K\left(D_{m}^{a}-D_{\max }^{b}\right)
$$

4) $D_{i}=f\left(D_{\max }\right)=S_{i} \cdot D_{\max }$ and $D_{a b n}=f\left(D_{\max }\right)=D_{m}^{\frac{1}{a}}+2 K\left(D_{\max }-D_{\max } \frac{b}{a}\right)$

$$
D_{i}=f\left(D_{m}\right)=S_{i} \cdot D_{m}{ }^{a} \text { and } D_{a b n}=f\left(D_{m}\right)=D_{m}+2 K\left(D_{m}{ }^{a}-D_{\max }{ }^{b}\right)
$$

\begin{tabular}{|c|c|c|c|c|c|c|c|c|c|c|c|c|c|c|}
\hline \multirow{2}{*}{ Dm } & \multirow{2}{*}{ Dmax } & \multirow{2}{*}{ Dabn } & Dmax $^{*}$ & \multicolumn{11}{|c|}{ Si (iso-Scoring Curves) } \\
\hline & & & $\min ($ Dmax,Dabn) & 1.00 & 0.90 & 0.80 & 0.70 & 0.60 & 0.50 & 0.40 & 0.30 & 0.20 & 0.10 & 0.00 \\
\hline 0.00 & 0.00 & 0.00 & 0.00 & 0.00 & 0.00 & 0.00 & 0.00 & 0.00 & 0.00 & 0.00 & 0.00 & 0.00 & 0.00 & 0.00 \\
\hline 0.10 & 0.14 & 0.17 & 0.14 & 0.14 & 0.13 & 0.11 & 0.10 & 0.08 & 0.07 & 0.06 & 0.04 & 0.03 & 0.01 & 0.00 \\
\hline 0.20 & 0.25 & 0.30 & 0.25 & 0.25 & 0.23 & 0.20 & 0.18 & 0.15 & 0.13 & 0.10 & 0.08 & 0.05 & 0.03 & 0.00 \\
\hline 0.30 & 0.36 & 0.42 & 0.36 & 0.36 & 0.32 & 0.29 & 0.25 & 0.22 & 0.18 & 0.14 & 0.11 & 0.07 & 0.04 & 0.00 \\
\hline 0.40 & 0.46 & 0.52 & 0.46 & 0.46 & 0.41 & 0.37 & 0.32 & 0.28 & 0.23 & 0.18 & 0.14 & 0.09 & 0.05 & 0.00 \\
\hline 0.50 & 0.55 & 0.62 & 0.55 & 0.55 & 0.50 & 0.44 & 0.39 & 0.33 & 0.28 & 0.22 & 0.17 & 0.11 & 0.06 & 0.00 \\
\hline 0.60 & 0.65 & 0.71 & 0.65 & 0.65 & 0.58 & 0.52 & 0.45 & 0.39 & 0.32 & 0.26 & 0.19 & 0.13 & 0.06 & 0.00 \\
\hline 0.70 & 0.74 & 0.79 & 0.74 & 0.74 & 0.66 & 0.59 & 0.52 & 0.44 & 0.37 & 0.30 & 0.22 & 0.15 & 0.07 & 0.00 \\
\hline 0.80 & 0.83 & 0.87 & 0.83 & 0.83 & 0.74 & 0.66 & 0.58 & 0.50 & 0.41 & 0.33 & 0.25 & 0.17 & 0.08 & 0.00 \\
\hline 0.90 & 0.91 & 0.94 & 0.91 & 0.91 & 0.82 & 0.73 & 0.64 & 0.55 & 0.46 & 0.37 & 0.27 & 0.18 & 0.09 & 0.00 \\
\hline 1.00 & 1.00 & 1.00 & 1.00 & 1.00 & 0.90 & 0.80 & 0.70 & 0.60 & 0.50 & 0.40 & 0.30 & 0.20 & 0.10 & 0.00 \\
\hline
\end{tabular}

5) Table 2: Numerical values of the iso-Score Curves of Case 2

Table 2: Numerical values of the iso-Score Curves of Case 2 


\section{$\underline{\text { Case } 3}$}

1) $S_{i}=40-10 \frac{B_{i}-B_{\min }}{B_{m}-B_{\min }}$ and $B_{a b n}=(1-T) A$

2) $S_{i}=1-0.25 \frac{D_{\max }-D_{i}}{D_{\max }-D_{m}}$ and $D_{a b n}=T$

3) $S_{i}=f\left(D_{\text {max }}\right)=1-0.25 \frac{D_{\text {max }}-D_{i}}{D_{\text {max }}-D_{\text {max }} \frac{1}{a}}$ and $D_{\text {abn }}=f\left(D_{\text {max }}\right)=T$

$$
S_{i}=f\left(D_{m}\right)=1-0.25 \frac{D_{m}{ }^{a}-D_{i}}{D_{m}{ }^{a}-D_{m}} \text { and } D_{\text {abn }}=f\left(D_{m}\right)=T
$$

4) $D_{i}=f\left(D_{\max }\right)=D_{\text {max }}-4\left(1-S_{i}\right)\left(D_{\text {max }}-D_{\max } \frac{1}{a}\right)$ and $D_{a b n}=f\left(D_{\max }\right)=T$

$$
D_{i}=f\left(D_{m}\right)=D_{m}{ }^{a}-4\left(1-S_{i}\right)\left(D_{m}{ }^{a}-D_{m}\right) \text { and } D_{a b n}=f\left(D_{m}\right)=T
$$

\begin{tabular}{|c|c|c|c|c|c|c|c|c|c|c|c|c|c|c|}
\hline \multirow{2}{*}{ Dm } & \multirow{2}{*}{ Dmax } & \multirow{2}{*}{ Dabn } & Dmax $^{\star}$ & \multicolumn{11}{|c|}{ Si (iso-Scoring Curves) } \\
\hline & & & $\min ($ Dmax,Dabn) & 1.00 & 0.90 & 0.80 & 0.70 & 0.60 & 0.50 & 0.40 & 0.30 & 0.20 & 0.10 & 0.00 \\
\hline 0.00 & 0.00 & 0.30 & 0.00 & 0.00 & 0.00 & 0.00 & 0.00 & 0.00 & 0.00 & 0.00 & 0.00 & 0.00 & 0.00 & 0.00 \\
\hline 0.10 & 0.14 & 0.30 & 0.14 & 0.14 & 0.12 & 0.11 & 0.09 & 0.08 & 0.06 & 0.04 & 0.03 & 0.01 & -0.01 & -0.02 \\
\hline 0.20 & 0.25 & 0.30 & 0.25 & 0.25 & 0.23 & 0.21 & 0.19 & 0.17 & 0.15 & 0.12 & 0.10 & 0.08 & 0.06 & 0.04 \\
\hline 0.30 & 0.36 & 0.30 & 0.30 & 0.30 & 0.30 & 0.30 & 0.30 & 0.30 & 0.30 & 0.30 & 0.30 & 0.30 & 0.30 & 0.30 \\
\hline 0.40 & 0.46 & 0.30 & 0.30 & & & & & & & & & & & \\
\hline 0.50 & 0.55 & 0.30 & 0.30 & & & & & & & & & & & \\
\hline 0.60 & 0.65 & 0.30 & 0.30 & & & & & & & & & & & \\
\hline 0.70 & 0.74 & 0.30 & 0.30 & & & & & & & & & & & \\
\hline 0.80 & 0.83 & 0.30 & 0.30 & & & & & & & & & & & \\
\hline 0.90 & 0.91 & 0.30 & 0.30 & & & & & & & & & & & \\
\hline 1.00 & 1.00 & 0.30 & 0.30 & & & & & & & & & & & \\
\hline
\end{tabular}

5) Table 3: Numerical values of the iso-Score Curves of Case 3

Table 3: Numerical values of the iso-Score Curves of Case 3 (Values higher than $T$ have not been calculated)

\section{References}

[1] W. R. Park, Construction Bidding for Profit, first ed., John Wiley \& Sons Inc, New Jersey, 1979.

[2] M.H. Rothkopf and R.M. Harstad "Modeling Competitive Bidding: A Critical Essay". Management Science. 40 (3) (1994) 364-384.

[3] S.G. Naoum "Critical Analysis of Time and Cost of Management and Traditional Contracts." Journal of Construction Engineering and Management. 120 (4) (1994) 687-705.

[4] W. Lo; C. L. Lin. and M. R. Yan, "Contractor's Opportunistic Bidding Behavior and Equilibrium Price Level in the Construction Market". Journal of Construction Engineering and Management. 133 (6) (2007) 409-416. 
[5] K. Ye; W. Jiang and L. Shen "Project competition intensity $(\mathrm{PCl})$ in the construction market: a case study in China". Construction Management and Economics. 26 (5) (2008) 463-470.

[6] M.H. Rothkopf "A Model of Rational Competitive Bidding". Management Science. 15 (7) (1969) 362-373.

[7] P. Näykki “On Optimal Bidding Strategies”. Management Science. 23 (2) (1976) 198-203.

[8] R. Engelbrecht-Wiggans "State of the Art-Auctions and Bidding Models: A Survey". Management Science. 26 (2) (1980) 119-142.

[9] R. Engelbrecht-Wiggans "The Effect of Regret on Optimal Bidding in Auctions". Management Science. 35 (6) (1989) 685-692.

[10] G. Deltas and R. Engelbrecht-Wiggans "Naive Bidding". Management Science. 51 (3) (2005) 328-338.

[11] R.M. Harstad and A. Saša Pekec "Relevance to Practice and Auction Theory: A Memorial Essay for Michael Rothkopf". Interfaces. 38 (5) (2008) 367-380.

[12] I. Dikmen, M. Talat and A. Kemal, "A case-based decision support tool for bid mark-up estimation of international construction projects" Automation in Construction, 17 (1) (2007) 30-44

[13] R.M. Skitmore, and D.S. Drew, and S. Ngai, "Bid-spread". Journal of Construction Engineering and Management. 127 (2) (2001) 149-153

[14] A. Fayek, "Competitive bidding strategy model and software system for bid preparation." Journal of Construction Engineering and Management. 124 (1) (1998) 1-10.

[15] R.M. Skitmore "Predicting the probability of winning sealed bid auctions: the effects of outliers on bidding models." Construction Management and Economics. 22 (1) (2004) 101 109.

[16] R.M. Skitmore, "The probability of tendering the lowest bid in sealed auctions: an empirical analysis of construction data". Journal of the Operational Research Society. 53 (1) (2002) 47-56.

[17] F. Roger, W. Lu, L. Shen, and J. Carol, "Competitiveness in construction: a critical review of research". Construction Management and Economics. 25 (9) (2007) 989-1000.

[18] W.K. Fu, D.S. Drew, and H.P. Lo. "Competitiveness of Inexperienced and Experienced Contractors in Bidding". Journal of Construction Engineering and Management. 129 (4), (2003) 388-395.

[19] M. Skitmore "First and second price independent values sealed bid procurement auctions: some scalar equilibrium results" Construction Management and Economics, 26 (8) (2008) 787-803

[20] R. M. Stark and M. H. Rothkopf. "Competitive bidding: A comprehensive bibliography." Journal of the Operational Research 27 (2) (1979) 364-390.

[21] L. Friedman "A competitive bidding strategy" Operations Research 1 (4) (1956) 104-12.

[22] J. C. Pim "Competitive tendering and bidding strategy" National Builder 55 (11) (1974) 541-545.

[23] R. McCaffer and A. N. Pettitt "Distribution of bids for buildings and road contracts" Operational Research Quarterly, 27 (4i) (1976) 835-43. 
[24] M. S. Mitchell "The probability of being the lowest bidder" Applied Statistics 2 (2) (1977) 191-4.

[25] R.M. Skitmore, A.N. Pettitt, and R. McVinish, "Gates' Bidding Model". Journal of Construction Engineering and Management. 133 (11) (2007) 855-863.

[26] M. Gates "Bidding strategies and probabilities" Journal of the Construction Division, Proceedings of the American Society of Civil Engineers, 93 (CO1) (1967) 75-107.

[27] R. I. Carr "General bidding model" Journal of the Construction Division, Proceedings of the American Society of Civil Engineers, 108 (CO4) (1982) 639-50.

[28] R.M. Skitmore "The contract bidder homogeneity assumption: an empirical analysis." Construction Management and Economics. 9 (5) (1991) 403-429.

[29] K. G. Runeson and R. M. Skitmore "Tendering theory revisited" Construction Management and Economics 17 (3) (1999) 285-96.

[30] S. Laryea and W. Hughes "Risk and Price in the Bidding Process of Contractors" Journal of Construction Engineering and Management 137 (4) (2011) 248-259

[31] B. Oo, D. S. Drew and G. Runeson "Competitor analysis in construction bidding" Construction Management and Economics, 28 (12) (2010) 1321-1329

[32] B. L. Oo, D. S. Drew and H. P. Lo "Heterogeneous Approach to Modeling Contractors' Decision-to-Bid Strategies" Journal of Construction Engineering and Management 134 (10) (2008) 766-776

[33] T. N. Cason, K. N. Kannan and Ralph Siebert "An Experimental Study of Information Revelation Policies in Sequential Auctions" Management Science 57 (4) (2011) 667-688

[34] R. Bapna, C. Dellarocas and S. Rice "Vertically Differentiated Simultaneous Vickrey Auctions: Theory and Experimental Evidence" Management Science 56 (7) (2010) 10741092

[35] L. Y. Chu "Truthful Bundle/Multiunit Double Auctions" Management Science 55 (7) (2009) 1184-1198

[36] P. Ioannou and R. E. Awwad "Below-Average Bidding Method" Journal of Construction Engineering and Management 136 (9) (2010) 936-947

[37] R. P. McAfee, J. McMillan. “Auctions and bidding." Journal Econom. Literature 25 (1987) 699-738

[38] R. Wilson "Strategic analysis of auctions." R. Aumann, S. Hart, eds. Handbook of Game Theory, Vol. 1. North-Holland/Elsevier Science Publishers, Amsterdam (1992) 227-279. 
[39] P. D. Klemperer "Auction theory: A guide to the literature" Journal Econom. Surveys 13 (3) (1999) 227-286.

[40] V. Krishna "Auction Theory" Academic Press, San Diego (2002)

[41] P. D. Klemperer "Auctions: Theory and Practice". Princeton University Press, Princeton, NJ (2004).

[42] P. R. Milgrom "Putting Auction Theory to Work" Cambridge University Press, Cambridge, UK (2004)

[43] D.W. Cattell, P.A. Bowen, and A.P. Kaka, "Review of Unbalanced Bidding Models in Construction". Journal of Construction Engineering and Management. 133 (8) (2007) 562573.

[44] Real Decreto Legislativo 2/2000, de 16 de junio, por el que se aprueba el texto refundido de la Ley de Contratos de las Administraciones Públicas. Boletín Oficial del Estado 148 (2000).

[45] P. Yeng-Horng J. Yi-Kai and Ch. Sheng-Fen "Exploring the Bidding Situation for Economically Most Advantageous Tender Projects Using a Bidding Game". Journal of Construction Engineering and Management. 132 (10) (2006) 1037-1042

[46] O. Abudayyeh, S.J. Zidan, S. Yehia, and D. Randolph, "Hybrid Prequalification-Based, Innovative Contracting Model Using AHP". Journal of Management in Engineering. 23 (2) (2007) 88-96.

[47] C. Hong "Contractor Performance Prediction Model for the United Kingdom Construction Contractor: Study of Logistic Regression Approach." Journal of Construction Engineering and Management. 130 (5) (2004) 691-698.

[48] A. Lim, Z. Xu, and F. Wang, "The bidding selection and assignment problem with minimum quantity commitment". Journal of the Operational Research Society. 59 (5) (2008) 693-702.

[49] D.K.H. Chua and D. Li "Key factors in bid reasoning model." Journal of Construction Engineering and Management. 126 (5) (2000) 349-357.

[50] H. Tsai, L. Wang, and L. Lin, "A study on improving the ranking procedure for determining the most advantageous tender". Construction Management and Economics. 25 (5) (2007) 545-554.

[51] K. Lam, M.C. Lam, and D. Wang, "MBNQA-oriented self-assessment quality management system for contractors: fuzzy AHP approach". Construction Management and Economics. 26 (5) (2008) 447-461.

[52] Y. Li, X. Nie, and S. Chen "Fuzzy Approach to Prequalifying Construction Contractors". Journal of Construction Engineering and Management. 133 (1) (2007) 40-49.

[53] M. E. Bayrakatar and M. Hastak "A decision support system for selecting the optimal contracting strategy in highway work zone projects" Automation in Construction, 18 (6) (2009) 834-843

[54] S. M. El-Sayegh "Multi-criteria decision support model for selecting the appropriate construction management at risk firm" Construction Management and Economics, 27 (4) (2009) 385-398 
[55] O. G. Manoliadis, J. P. Pantouvakis and S. E. Christodoulou "Improving qualificationsbased selection by use of the fuzzy Delphi method" Construction Management and Economics, 27 (4) (2009) 373-384

[56] J. P. Pastor-Ferrando, P. Aragonés-Beltrán, A. Hospitaler-Pérez and M. García-Melón "An ANP- and AHP-based approach for weighting criteria in public works bidding" Journal of the Operational Research Society 61 (special issue) (2010) 905-916

[57] T.S. Liao, M.T. Wang, and H.P. Tserng, "A framework of electronic tendering for government procurement: a lesson learned in Taiwan" Automation in Construction, 11 (6) (2002) 731-742

[58] D. Drew, L. Shen and P. Zoy "Developing an optimal bidding strategy in two-envelope fee bidding." Construction Management and Economics. 20 (1) (2002) 611-620.

[59] D. Drew, S. Tang and S.O. Lo "Developing a tendering strategy in two-envelope fee tendering based on technical score-fee variability." Construction Management and Economics. 20 (1) (2002) 67-81.

[60] L. Chao, and C. Liou "Risk-minimizing approach to bid-cutting limit determination". Construction Management and Economics. 25 (8) (2007) 835-843.

[61] Y. Cao, S. Wang, and H. Li, "Automatic recognition of tables in construction tender documents" Automation in Construction, 11 (5) (2002) 573-584. 